\title{
Correction to: Genic Molecular Markers in Fungi: Availability and Utility for Bioprospection
}

\author{
Anirudha Chattopadhyay, Kapil Kumar Tiwari, Kul Bhushan, \\ and Dharmendra Pratap
}

\section{Correction to:}

B.P. Singh, V.K. Gupta (eds.), Molecular Markers in Mycology, Fungal Biology, https://doi.org/10.1007/978-3-319-34106-4_7

In the original version of chapter 7, the author's complete name currently appears as Kulbhushan Chaudhary. The complete name has been corrected as Kul Bhushan and the email address has also been updated as 1sr_bhushan@ $@$ rediffmail.com ${ }^{凶}$ 